\title{
Evaluation of the use of venous thromboembolism prophylaxis in hospitalised medical patients
}

\author{
${ }^{1} \mathrm{M}$ Panju, ${ }^{2} \mathrm{D}$ Raso, ${ }^{3} \mathrm{~A}$ Patel, ${ }^{4} \mathrm{~A}$ Panju, ${ }^{5} \mathrm{~J}$ Ginsberg \\ 'Clinical Scholar, Department of Medicine; ${ }^{2}$ Fellow, Critical Care, Department of Medicine; ${ }^{3,4}$ Professor, Department of Medicine; ${ }^{5}$ Professor, \\ Department of Medicine and Haematology and Thromboembolism, McMaster University Medical Center, Hamilton, Ontario, Canada
}

\section{ABSTRACT}

Background: Venous thromboembolism (VTE) prophylaxis is effective in the prevention of deep vein thrombosis (DVT) and pulmonary embolism (PE) in medical patients.

Methods: A retrospective chart review was performed on medical inpatients at two academic hospitals in Hamilton, Ontario to investigate if patients receivedVTE prophylaxis as per current guidelines.

Results: An analysis was performed on 762 patient charts and 170 met inclusion criteria for use of pharmacological VTE prophylaxis. Of these, 9I (54\%) received pharmacological VTE prophylaxis. In 63 patients with a contraindication to pharmacological VTE prophylaxis, 16 (25\%) received non-pharmacological VTE prophylaxis.

Conclusion: The provision rate of pharmacologicalVTE prophylaxis in hospitalised medical patients who met pre-defined clinical criteria for prophylaxis was $54 \%$. The rate of prophylaxis increased with additionalVTE risk factors to a peak rate of $67 \%$. There is room for the development of strategies to improve the use of VTE prophylaxis in hospitalised medical patients.

KEYWORDS Venous thromboembolism, prophylaxis, deep vein thrombosis

DECLARATION OF INTERESTS Dr Ginsberg is a Career Investigator of the Heart and Stroke Foundation of Ontario and holds The David Braley and Nancy Gordon Chair in Thromboembolic Disease.

\section{INTRODUCTION}

Venous thromboembolism (VTE), which includes deep vein thrombosis (DVT) and pulmonary embolism (PE), is a major cause of mortality and morbidity in hospitalised medical patients.' Greater than $25 \%$ of all VTE are associated with hospitalisation and $50-75 \%$ of these cases occur in medical inpatients. ${ }^{2,3}$ Without prophylaxis, the risk of VTE in hospitalised medical patients is $10-15 \%$ and can be even higher in patients with additional risk factors such as myocardial infarction (MI), congestive heart failure (CHF), cerebrovascular accident (CVA), chronic obstructive pulmonary disease (COPD), malignancy, sepsis, inflammatory bowel disease or previous VTE. ${ }^{4}$ The US Agency for Healthcare Research and Quality ranked VTE prevention as the first priority out of 79 that can improve patient safety in the healthcare setting. ${ }^{5}$

Venous thromboembolism prophylaxis has been shown to prevent DVT and possibly PE in hospitalised medical patients. Meta-analyses have shown that pharmacological VTE prophylaxis significantly reduces the development of DVT and symptomatic PE. ${ }^{6,7}$ The use ofVTE prophylaxis has been given a strong (level IA) recommendation by the 2008 American College of Chest Physicians (ACCP) Antithrombotic and Thrombolytic Evidence Based Clinical Guidelines ${ }^{8}$ and the Scottish Intercollegiate Guidelines Network.' The National Institute for Health
Correspondence to M Panju, Room B3- 49 Juravinski Hospital and Cancer Center,

7 I I Concession Street, Hamilton, Ontario,

L8V IC3, Canada

tel. + I 90552 I 2100 ext 73953

e-mail

mohamed.panju@medportal.ca and Clinical Excellence (NICE) has also issued similar guidelines recommendingVTE prophylaxis in hospitalised medical patients. ${ }^{10}$

Recent studies have indicated that pharmacological prophylaxis is underutilised in medical inpatients. Although most hospitalised medical patients have an indication forVTE prophylaxis, data from North American and international studies have shown that less than onethird receive adequate VTE prophylaxis in hospital. ${ }^{11-13}$

We evaluated the use of VTE prophylaxis in hospitalised medical patients at two academic tertiary care centres in Hamilton, Ontario. Our goal was to determine the rates of prophylaxis in medical inpatients and determine if patients with predefined additional risk factors for VTE were more likely to receive prophylaxis. We also wanted to identify the method of prophylaxis and determine the rate of mechanical prophylaxis in patients who had contraindications to pharmacological prophylaxis.

\section{METHODS}

\section{Hospital selection}

Potentially eligible patients were admitted to one of the general medical wards of two teaching hospitals at Hamilton Health Sciences: the McMaster University Medical Centre (MUMC) or the Hamilton General Hospital 
$(\mathrm{HGH})$. The General is a centre of excellence for cardiac disease and stroke and has an acute stroke as well as a noncoronary care unit (CCU) cardiology department. Subjects were recruited only from those patients admitted to the general medicine ward of both sites.

\section{Patients}

The medical charts from 762 consecutive patients from the two sites were reviewed using a start date of I January 2007. Patients were included in the analysis if they were older than 18 years, and were admitted directly from the emergency department to a medical ward for three or more days with a diagnosis of $\mathrm{CHF}$, severe respiratory infection, acute neurological disease, inflammatory or metabolic process or acute infectious process. Acute inflammatory diseases included inflammatory bowel disease, electrolyte imbalances and rheumatologic diseases.

Patients who required anticoagulation for atrial fibrillation, acute coronary syndrome,VTE or any other reason were excluded from the study. Patients were also excluded if they were transferred from another service or admitted to the intensive care unit during their hospitalisation.

A priori, eligible patients were subcategorised into those considered to have (or not have) a contraindication for pharmacological VTE prophylaxis if they had: I) a haemoglobin of less than $100 \mathrm{~g} / \mathrm{L}$ plus suspected bleeding 2 ) active bleeding 3 ) a gastrointestinal bleed within the past three months 4) a previous diagnosis of heparininduced thrombocytopenia (HIT) or 5) a platelet count of less than $100 \times 109 / \mathrm{L}$. These patients were not excluded from the study, but were evaluated for the use of mechanical prophylaxis.

The hospital charts were evaluated by trained research assistants. Information was abstracted onto standardised case report forms. The information compiled by the research assistants was audited by two investigators (Dr M Panju and Dr D Raso) and there was full agreement with the method of data compilation.

\section{Accepted VTE prophylaxis}

Patients were only considered to be receiving appropriate pharmacological VTE prophylaxis if they received appropriate doses of subcutaneous unfractionated heparin $(\mathrm{UH})$ or low molecular weight heparin (LMWH) as per the 2008 ACCP guidelines. Appropriate dosages included: UH 5000 Units BID or TID, enoxaparin $40 \mathrm{mg}$ daily or $30 \mathrm{mg}$ BID or $30 \mathrm{mg}$ daily if calculated creatinine clearance was less than 30 $\mathrm{cc} / \mathrm{min}$, dalteparin 5000 units daily or fondaparinux 2.5 $\mathrm{mg}$ daily (subcutaneously).

Aspirin or clopidogrel alone, or in combination, was not considered appropriate VTE prophylaxis.
The use of mechanical compression was considered appropriate prophylaxis in patients who had a contraindication to pharmacologic agents. An order of 'activity as tolerated' was not considered appropriate VTE prophylaxis.

\section{Additional risk factors}

Prior investigation into medical inpatients identified patient age greater than 75, cancer, prior VTE, acute infectious disease, chronic respiratory disease, immobility and surgery within the past six months as independent risk factors for developing a VTE during hospitalisation. ${ }^{4}$ All reviewed charts were stratified based on number of risk factors.

\section{Ethics}

This study was approved by the Research and Ethics Board at McMaster University, Ontario.

\section{RESULTS}

\section{Data acquisition}

A total of 762 charts were reviewed, 38I from each site. There were 45 charts excluded because of insufficient information. An additional 322 charts were excluded because they did not meet the inclusion criteria (I7I from $\mathrm{HGH}$ and I5I from MUMC). The most common inclusion criterion not met was admission less than three days. Of the remaining 395 charts, 162 met the exclusion criteria (86 from Hamilton General Hospital $(\mathrm{HGH})$ and 76 from McMaster University Medical Centre (MUMC), leaving 233

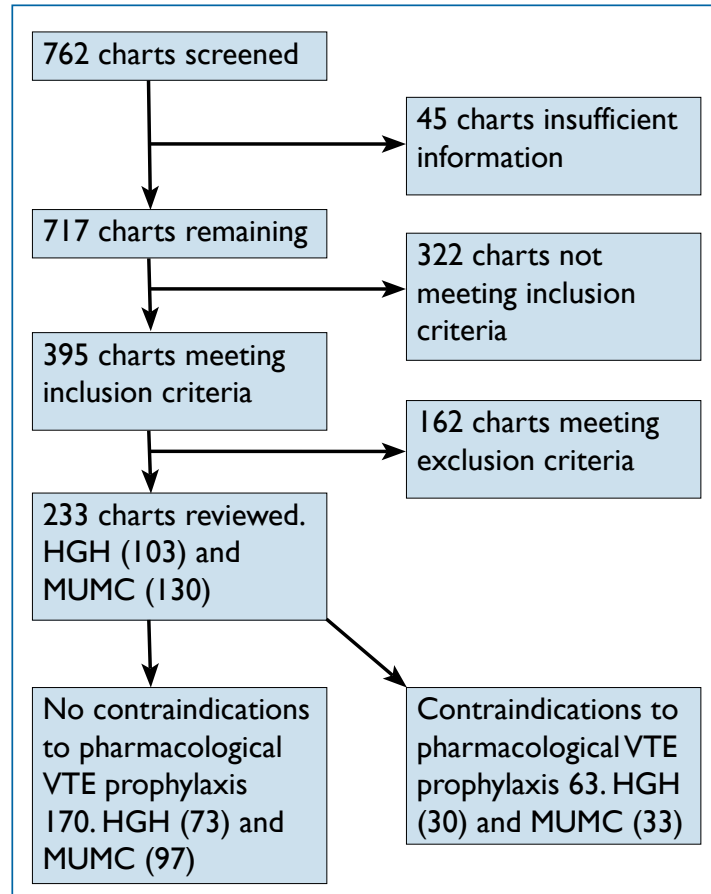

FIGURE I Selection criteria of 762 consecutive charts from Hamilton General Hospital (HGH) and McMaster University Medical Centre (MUMC) from I July 2007. 
charts for possible inclusion. Of these, 63 patients were considered to have a contraindication to pharmacological VTE prophylaxis, while I70 patients did not (Figure I).

\section{Prophylaxis rates}

The VTE prophylaxis rates were similar in the two participating hospitals. When pharmacological VTE prophylaxis was indicated, $48 \%$ of patients at the HGH and $58 \%$ of patients at MUMC received appropriate prophylaxis. The two sites had a combined prophylaxis rate of $54 \%$ (Table I).

TABLE I Eligible patients receiving pharmacological VTE prophylaxis at McMaster University Medical Centre, Hamilton General Hospital and combined

\begin{tabular}{|l|l|l|l|}
\hline & $\begin{array}{l}\text { McMaster } \\
\text { University } \\
\text { Medical } \\
\text { Centre }\end{array}$ & $\begin{array}{l}\text { Hamilton } \\
\text { General } \\
\text { Hospital }\end{array}$ & Combined \\
\hline $\begin{array}{l}\text { Total number } \\
\text { of patients } \\
\text { receiving } \\
\text { pharmaco- } \\
\text { logicalVTE } \\
\text { prophylaxis }\end{array}$ & $56 / 97(58 \%)$ & $35 / 73(48 \%)$ & $91 / 170(54 \%)$ \\
\hline
\end{tabular}

\section{Additional risk factors}

There was an increase in VTE prophylaxis rates with additional risk factors: $67 \%$ for one and $66 \%$ for two or more. Patients with no additional risk factors had very low VTE prophylaxis rates (I3\%) (Table 2).

TABLE 2 Eligible patients receiving pharmacological VTE prophylaxis based on additional risk factors including prior VTE, age greater than 75 years, diagnosis of cancer, chronic respiratory disease, immobility or surgery within the last six months

\begin{tabular}{|c|l|l|l|}
\hline $\begin{array}{l}\text { Number of } \\
\text { additional } \\
\text { risk factors }\end{array}$ & $\begin{array}{l}\text { McMaster } \\
\text { University } \\
\text { Medical } \\
\text { Centre }\end{array}$ & $\begin{array}{l}\text { Hamilton } \\
\text { General } \\
\text { Hospital }\end{array}$ & Combined \\
\hline 0 & $3 / 23(13 \%)$ & $2 / 17(12 \%)$ & $5 / 40(13 \%)$ \\
\hline 1 & $20 / 28(71 \%)$ & $18 / 29(62 \%)$ & $38 / 57(67 \%$ \\
\hline $2+$ & $33 / 46(72 \%$ & $15 / 27(56 \%)$ & $48 / 73(66 \%)$ \\
\hline
\end{tabular}

\section{Admission diagnosis}

VTE prophylaxis rates were reviewed based on the admission diagnosis. The highest prophylaxis rates were seen in patients with heart failure. The overall prophylaxis rates were similar for different diagnoses (Table 3).

\section{Forms of VTE prophylaxis}

Unfractionated heparin, 5000 units subcutaneously twice daily, was the most frequently used pharmacological prophylaxis $(95 \%)$, while $\mathrm{LMWH}$ was used $3 \%$ of the time and fondaparinux was used $2 \%$ of the time (Table 4 ).
TABLE 3 Patients receiving pharmacological VTE prophylaxis based on admission diagnosis

\begin{tabular}{|l|l|l|l|}
\hline $\begin{array}{l}\text { Patient } \\
\text { admission } \\
\text { diagnosis }\end{array}$ & $\begin{array}{l}\text { McMaster } \\
\text { University } \\
\text { Medical } \\
\text { Centre }\end{array}$ & $\begin{array}{l}\text { Hamilton } \\
\text { General } \\
\text { Hospital }\end{array}$ & Combined \\
\hline Heart failure & $3 / 7(43 \%)$ & $5 / 6(83 \%)$ & $8 / 13(62 \%)$ \\
\hline $\begin{array}{l}\text { Acute } \\
\text { respiratory } \\
\text { disease }\end{array}$ & $6 / 9(67 \%)$ & $5 / 1 \mathrm{I}(45 \%)$ & $1 \mathrm{I} / 20(55 \%)$ \\
\hline $\begin{array}{l}\text { Acute } \\
\text { neurological } \\
\text { disease }\end{array}$ & $9 / 15(60 \%)$ & $12 / 23(52 \%)$ & $2 \mathrm{I} / 38(55 \%)$ \\
\hline $\begin{array}{l}\text { Infectious } \\
\text { process or } \\
\text { sepsis }\end{array}$ & $19 / 35(54 \%)$ & $7 / 20(35 \%)$ & $26 / 54(48 \%)$ \\
\hline $\begin{array}{l}\text { Acute } \\
\text { inflammatory } \\
\text { or metabolic } \\
\text { disease }\end{array}$ & $13 / 29(45 \%)$ & $6 / 12(50 \%)$ & $19 / 4 \mathrm{I}(46 \%)$ \\
\hline $\begin{array}{l}\text { Chest pain } \\
\text { not yet } \\
\text { diagnosed }\end{array}$ & $1 / 2(50 \%)$ & $0 / I(0 \%)$ & $1 / 3(33 \%)$ \\
\hline
\end{tabular}

\section{Contraindication to pharmacological prophylaxis}

There were 63 patients ( 30 at $\mathrm{HGH}$ and 33 at MUMC) who had a contraindication to pharmacological prophylaxis and 16 (25\%) of these were treated with either compression stockings or an intermittent pneumatic compression device (Table 5).

TABLE 4 Types of pharmacologicalVTE prophylaxis received

\begin{tabular}{|l|l|l|l|}
\hline & $\begin{array}{l}\text { Un- } \\
\text { fractionated } \\
\text { heparin } \\
\text { (UH) }\end{array}$ & $\begin{array}{l}\text { Low } \\
\text { molecular } \\
\text { weight } \\
\text { heparin } \\
\text { (LMWH) }\end{array}$ & $\begin{array}{l}\text { Fonda- } \\
\text { parinux }\end{array}$ \\
\hline $\begin{array}{l}\text { McMaster } \\
\text { University } \\
\text { Medical } \\
\text { Centre }\end{array}$ & $48(86 \%)$ & $5(9 \%)$ & $3(5 \%)$ \\
\hline $\begin{array}{l}\text { Hamilton } \\
\text { General } \\
\text { Hospital }\end{array}$ & $53(100 \%)$ & 0 & 0 \\
\hline Total & $\mathbf{1 6 2 ( 9 5 \% )}$ & $\mathbf{5 ( 3 \% )}$ & $\mathbf{3 ( 2 \% )}$ \\
\hline
\end{tabular}

\section{DISCUSSION}

The development of VTE is a significant cause of morbidity and mortality for hospitalised medical patients. Despite effective prophylaxis options, the rate of prophylaxis remains suboptimal.

In our study, only $54 \%$ of patients received appropriate VTE prophylaxis as per current clinical guidelines. A similar study undertaken in Hamilton in 2003 showed a rate of VTE prophylaxis of $33 \%$. Although making formal 
TABLE 5 Rates of mechanical prophylaxis

\begin{tabular}{|l|l|l|l|}
\hline & $\begin{array}{l}\text { McMaster } \\
\text { University } \\
\text { Medical } \\
\text { Centre }\end{array}$ & $\begin{array}{l}\text { Hamilton } \\
\text { General } \\
\text { Hospital }\end{array}$ & Combined \\
\hline $\begin{array}{l}\text { Prophylaxis in } \\
\text { patients with a } \\
\text { contra- } \\
\text { indication to } \\
\text { pharmacologic } \\
\text { therapy }\end{array}$ & $8 / 33(24 \%)$ & $8 / 30(26 \%)$ & $16 / 63(25 \%)$ \\
\hline
\end{tabular}

comparisons with historical data is problematic, the prophylaxis rates appear to have improved, but remain suboptimal. This study also shows that patients with increased risk factors are more likely to receive prophylaxis, suggesting physicians are familiar with VTE risk factors and have incorporated this knowledge into their decision-making. Low rates of VTE prophylaxis have been documented in Canadian, US and international studies. The multicentre Canadian CURVE study showed the Canada-wide VTE prophylaxis rate to be $16 \% .{ }^{14} \mathrm{~A}$ multicentre US study has shown the appropriate VTE rate as only $33.9 \% .{ }^{2}$ The Epidemiologic International Day for the Evaluation of Patients at Risk for Venous Thromboembolism in the Acute Hospital Care Setting (ENDORSE) study showed the VTE prophylaxis rate to be only $39 \% .^{13}$

This study was a retrospective chart review and subject to the biases inherent in such a study. Presence of risk factors and immobility may not have been accurately reported in the documentation available for review. Additionally, the study population was composed of patients from two Hamilton hospitals which are part of a single teaching centre, McMaster University, which may not be representative of practice patterns in other academic centres or in community hospitals. McMaster University is a centre of excellence for thrombosis, and one would expect the prophylaxis rates to be even lower in community-based hospitals. Therefore, we suspect that a $54 \%$ prophylaxis rate at McMaster-based hospitals is likely to be higher than the prophylaxis rates in other surrounding community hospitals. The relatively low rate of prophylaxis may also be explained in part by the presence of a dedicated thrombosis service at both study hospitals. This service does not routinely consult on medical patients but its presence may cause complacence by other treating physicians. The rate of mechanical VTE prophylaxis used in patients with a contraindication to pharmacological treatment was low. This is possibly due to lack of knowledge translation for non-pharmacological strategies for VTE prophylaxis.

The most common form of VTE prophylaxis was UH 5000 Units BID. There was very little use of LMWH. At $\mathrm{HGH}, 100 \%$ of the pharmacological prophylaxis was $\mathrm{UH}$. The benefits of LMWH include possible increased efficacy, lower risk of developing heparin-induced thrombocytopenia (HIT) and once daily dosing. LMWH was available for use at both sites. Our study was not designed to determine why LMWH was not used as often as one may have expected. The minimal use of LMWH may have been related to a lack of knowledge of the advantages of $\mathrm{LMWH}$, concern about the cost of LMWH or simply familiarity with UH.

Given the evidence supporting its use, it is unclear why the rates of VTE prophylaxis were not higher. One explanation is that we based our inclusion criteria for patient and anticoagulant selection on the 2008 ACCP guidelines ${ }^{8}$, which are not universally accepted. The lack of knowledge about the benefits of VTE prophylaxis may also explain the low rates of prophylaxis. Better dissemination of current guidelines to the students and resident physicians who are often responsible for admitting patients might overcome this problem. It should also be noted that the majority of admitted medical patients have several acute medical issues and primary prevention strategies such as VTE prophylaxis are not a priority on admission andVTE prophylaxis may have been an oversight. Furthermore, several of these additional medical issues increase the risk of VTE. This study did not directly evaluate the cause of noncompliance to VTE prophylaxis.

Development of a systems approach may increase the use of VTE prophylaxis and other prevention strategies. This approach could include the presence of dedicated quality assurance health professionals on medical floors with a specific role to ensure that health safety measures such as VTE prophylaxis have been implemented. There is also a role for hospital pharmacists to provide reminders forVTE prophylaxis or for computer prompts for institutions using computer order entry for medical inpatients. There is evidence that pre-printed written orders improveVTE prophylaxis rates. ${ }^{15}$ Further research will need to focus on system improvements, which can improve VTE prophylaxis rates along with other preventive health measures.

Acknowledgements: We would like to thank Frances Dinning and Sharon Hendershott for their administrative help. 


\section{REFERENCES}

I Spyropoulos A. Emerging strategies in the prevention of venous thromboembolism in hospitalised medical patients. Chest 2005; 128:958-69. http://dx.doi.org/10.1378/chest.128.2.958

2 Amin A, Stemkowski S, Lin J et al.Thromboprophylaxis rates in US medical centers: Success or failure? J Thromb Haemost 2007; 5:I6 I0-16. http://dx.doi.org/I0. I I I /j.I538-7836.2007.02650.x

3 Samama MM, Cohen AT, Darmon JY et al. A comparison of enoxaparin with placebo for the prevention of venous thromboembolism in acutely ill medical patients. New Engl J Med 1999; 341:793-800. http:// dx.doi.org/I0.1056/NEJMI999090934III 03

4 Anderson FA, Spencer FA. Risk factors for thromboembolism. Circulation 2003; 107:19-II6. http://dx.doi.org/I0.II6I/0I. CIR.0000078469.07362.E6

5 Maynard G, Stein J, The Society of Medicine. Preventing hospitalacquired venous thromboembolism: a guide for effective quality improvement [Internet]. Rockville, MD: Agency for Healthcare Research and Quality; 2008 [cited 20II Oct 3]. Available from: http://www.ahrq.gov/qual/vtguide/vtguide.pdf

6 Dentali F, Douketis JD, Gianni M et al. Meta-analysis: anticoagulant prophylaxis to prevent symptomatic venous thromboembolism in hospitalised medical patients. Ann Intern Med 2007; 146:278-88.

7 Wein L, Wein S, Haas SJ et al. Pharmacological venous thromboembolism prophylaxis in hospitalised medical patients: a meta-analysis of randomized controlled trials. Arch Intern Med 2007; 167:1476-86.http://dx.doi.org/I0.1001/archinte.167.14.1476

8 Geerts WH, Bergquist D, Pineo GF et al. Prevention of venous thromboembolism: American College of Chest Physicians evidence-based clinical practice guidelines (8th Edition). Chest 2008; I 33:38IS-453S. http://dx.doi.org// 0.1378/chest.08-0656
9 Scottish Intercollegiate Guidelines Network (SIGN). Prevention and management of venous thromboembolism. A national clinical guidelines [Internet]. SIGN; 2010 [cited 20II Sept 29]. Available from: http://www.sign.ac.uk/pdf/sign I 22.pdf

I0 National Institute for Health and Clinical Excellence (NICE).Venous thromboembolism: reducing the risk. NICE clinical guidelines [Internet]. NICE; 2010 [cited 20II Sept 29]. Available from: http:// www.nice.org.uk/nicemedia/pdf/CG92NICEGUIDELINEPDF.pdf

I I Rahim SA, Panju A, Pai M et al. Venous thromboembolism prophylaxis in medical patients: a retrospective chart review. Thromb Res 2003; I I I:215-19. http://dx.doi.org/10.1016/j.thromres.2003.09.010

12 Piazza G, Seddighzadeh A, Goldhaber SZ. Double trouble for 2,609 hospitalised medical patients who developed deep vein thrombosis: prophylaxis omitted more often and pulmonary embolism more frequent. Chest 2007; 132:554-6I. http://dx.doi.org/I0.1378/ chest.07-0430

13 Cohen AT, Tapson VF, Jean-Francois B et al. Venous thromboembolism risk and prophylaxis in the acute hospital setting (ENDORSE Study): a multinational cross-sectional study. Lancet 2008; 37I:387-94. http://dx.doi.org/I0.I0I6/S0I40-6736(08)60202-0

14 Kahn SR, Panju A, Geerts W et al. Multicentre evaluation of the use of venous thromboembolism prophylaxis in acutely ill medical patients in Canada. Thromb Res 2007; I 19; 145-55. http://dx.doi.org/I0.1016/j. thromres.2006.01.0II

I5 O'Connor C, Adhikari NKJ, Decaire K et al. Medical admission order sets to improve deep vein prophylaxis rates and other outcomes. J Hosp Med 2009; 4;8I-89. http://dx.doi.org/I0.1002/jhm.399

\section{CONFERENCING AND EVENTS}

The Royal College of Physicians of Edinburgh has a unique blend of rooms providing the perfect location for your conference, meeting or event. The Victorian Great Hall, galleried New Library and the Georgian Cullen Suite are wonderful settings for dinners and receptions. The modern Conference Centre seats up to 300 people in raked seating and is complemented by breakout rooms seating from 10 to 150 people, a keypad voting system and video conferencing. The College provides a stunning setting for weddings and receptions and is licensed for both civil and religious ceremonies. Discounts are available for Fellows and Members, medical conferences and charities.

For more information or for a quotation, please contact the Events Team on +44 (0) I3I 225 7324; email events@rcpe.ac.uk or visit http://www.rcpe-venue.co.uk



